\title{
Stereotypical Views of Private Sector Employees about Public Sector Employees' Performance in Kingdom of Bahrain
}

\author{
Dr. Amira Karam Eldin, Assistant Professor \\ University College of Bahrain, Kingdom of Bahrain
}

doi: 10.19044/esj.2016.v12n2p127 URL:http://dx.doi.org/10.19044/esj.2016.v12n2p127

\begin{abstract}
The researcher observed a widely-held stereotype about the performance of the public-sector employees in general society discourse, and especially with private-sector employees. Public-sector employees are taken as individuals who settle at mediocre performance. This research aims to test these observations using hypothesis analysis. One questionnaire was distributed on a sample of private sector employees to survey their perceptions about public sector employees' performance. Another questionnaire was distributed on a sample of public sector employees to find whether they are aware of these stereotypical views, and whether this awareness causes frustration emotions.

H1: private-sector employees have negative stereotypical views about public-sector employees’ performance

H2: public sector employees know about the negative stereotypes held by private-sector employees about their performance

H3: public sector employees experience emotions of frustration by the negative stereotypes held by private-sector employees about their performance
\end{abstract}

Two self-administered questionnaires were designed, one for the private sector employees to survey their perceptions about the public sector employees' performance, and the other one for public sector employees to survey whether they are aware about these stereotypes, and whether this awareness produces emotions of frustration. The questionnaires included demographic questions, close-ended questions and one open question for remarks. The Likert scale was used for close-ended questions to seek the respondents' opinions on a list of statements.

The results validated all hypotheses. Nonetheless, we found that the stereotypes are not deeply embedded. In essence, we argue that they represent a manifestation of customer dissatisfaction gained from private sector employees' experiences with public sector front offices. These 
findings highlight the importance of maintaining high level front-office services at the public sector as the disappointments are generalized to the organizations in whole and all their employees.

Keywords: Employees, stereotypes, Bahrain

\section{Introduction}

The researcher observed a widely held stereotype about the performance of public sector employees in general society discourse, and especially with private sector employees. Public sector employees are taken as individuals who settle at mediocre performance and who would not pay any extra effort to exceed expectations. The researcher predicted that knowing these stereotypes can trigger frustration with public sector employees. This research attempts to support these observations with empirical evidence using two samples from the private and public sectors at the Kingdom of Bahrain.

The paper uses hypothesis analysis to test the above observations. The paper starts with a brief literature review followed by a section explaining methodology. After that, the results are presented with a discussion of the main observations. The paper ends with the limitations of this research, and recommendations for future research.

\section{Literature Review}

According to Cambridge Online Dictionary, the term 'stereotype' is a 'fixed idea that people have about what someone or something is like, especially an idea that is wrong'. The term first came into use over 200 years ago. Having Greek and Latin roots, it was used to describe how a stereotype, or a stamp, was used to print identical copies of documents (Valiulis, O’Driscoll \& Redmond, 2007). Accordingly, a stereotypical view is characterized with rigidity and excessive generalization.

Stereotyping happens when people are identified simply based on their membership in a certain social category. When people are stereotyped, they are reduced to one positive or negative characteristic in a way that suggests that this characteristic is naturally built into them (Valiulis, O’Driscoll \& Redmond, 2007). In that sense, stereotyping can ignorantly reduce the individuality of a human being to one characteristic or number of characteristics shared by the group at which the stereotype is directed.

The motives for stereotyping are not always vicious. Stereotyping provides a number of profits for their users. For instance stereotypes work as an aid of explanation as they help the explainer to transfer a piece of information to the perceiver as fast as possible. And in that sense, stereotypes can save time and energy (McGarty, Yzerbyt \& Spears, 2002). Therefore, 
stereotyping can appeal to both the explainer and the perceiver to accentuate a sense of coherence. In addition to being based on superficial knowledge and unnecessarily applicable information (Valiulis, O’Driscoll \& Redmond, 2007), one can argue that stereotyping can be an ignorant quest for convenience and discriminatory harmony.

Stereotypes can operate on several levels of the society; within individuals, families, and groups. On a bigger level, it can take place between groups, in public places, and in social language and discourse. Stereotypes can extend to a cultural level where they are expressed in art works, literature, and in the media. Furthermore, stereotypes appear at a political level; they can be maintained in government policies, political language and discourse (Valiulis, O’Driscoll \& Redmond, 2007).

\section{Stereotypes and performance}

Perhaps the most commonly known effects of stereotyping are inequalities experienced by groups and individuals. This is evident in how stereotyped people are accorded by the society. When stereotypical images are portrayed, assumptions are made and perspectives are communicated serving to perpetuate unfounded myths about a group and its individual members, to limit the choices that are open to individuals of the stereotyped group, and to shape expectations of the group towards individuals (Valiulis, O’Driscoll \& Redmond, 2007).

Stereotypes do not just reflect an individual or societal way of thinking, but are also manifested in organizational practices, policies and procedures laying ground to intentional and unintentional discrimination. From a managerial perspective, individuals' abilities and potentials can easily be underestimated once they are associated with stereotypes. If stereotyping goes unchecked in an organization, it can cause unwarranted stress and disharmony among employee (Valiulis, O’Driscoll \& Redmond, 2007).

Stereotypes can have psychological and behavioral consequences on their subjects. The evidence on their effects remains mixed (Gray et al., 2002). Stereotypes can be positive and negative. Both types can operate in a rather complex way. For example, it was found that high achievers are more prone to get annoyed by stereotypes. On one hand, they strive to meet the positive stereotypes that their employers and colleagues hold for them, while on another hand, they pay extra effort to avoid performing in resemblance with negative stereotypes that can be associated with them such as gender and race stereotypes (Conaway, 2005).

The effects of stereotypes on both perception and behavior were found to be rather automatic than controlled (Devine, 1989). The concept of stereotype threat refers to a situation were the subject of a stereotype exhibits behaviors confirming the stereotype about one's group; a situation that makes 
it difficult for people to perform up to their potential (Buyens et al., 2009) or to exhibit their true personality traits. Confirming a stereotype can be done subconsciously; an individual may believe the stereotypes, and consequently be victimized by an illusion that one is unable to beat the stereotype. Stereotypes can also be confirmed consciously: an individual can deliberately reject to invest effort that will fall denied or unnoticed (Buyens et al., 2009).

\section{Stereotypes and self-image}

More alarmingly, individuals can embed the stereotypes in their selfimage (Buyens et al., 2009) pulling around a thread of consequences on selfconfidence, self-esteem, and self-efficacy. These attributes are pivotal during organizational change phases. An employee who embedded a low performer stereotype in one's self-image is likely to feel like an outsider during initiatives of performance uplifting. This situation creates a cycle of low performance triggered by a stereotype and going through the experience of confirming the stereotype (Buyens et al., 2009). Research was successful in empirically displaying this cycle in older people's performance in the workplace (Buyens et al., 2009), and lower socioeconomic students' performance in intellectual ability tests (Croizet, 1998).

To minimize the impact of a stereotype, Valiulis, O’Driscoll \& Redmond (2007) argued that the society can actively challenge the stereotype using a set of steps: raising awareness of how stereotyping happens and its negative impact; promoting communication and debate with a view of creating images and language that more accurately reflects the variety in the experience and situations of groups and a individuals; and implementing good practices to diminish the role that stereotyping plays in decisions, policies, and practices in organizations.

A counter argument was made by Devine (1989) that the process of removing stereotypes and their cognitive implications is challenging. She argued that as long as a stereotype exists, prejudice will inevitability follow. The explainer and perceiver of the stereotype must make active effort to stop the automatic cognitive processes about a stereotype. Equally challenging, the subject of a stereotype must strive to be conscious about the stereotype threat and exert willpower to display the most suitable behaviors, whether confirming or nullifying the stereotypes.

\section{Corporate reputation and employees}

Just like individuals, organizations have reputations. The concept of corporate reputation was introduced to the literature 40 years ago. Corporate reputation refers to collective views about an organization by all stakeholders. The concept is under researched for government organizations 
(Da Silva \& Batista, 2007). However, government organizations are known in both literature and practice as bureaucratic, slow, and irresponsive to public needs. The available literature on government performance commonly discusses reforms, restructuring and cutting costs in a target of transforming management style to a private-sector like (Luoma-aho, 2008).

An organization's reputation provides information on its performance. For instance, good organization's reputation reflects high level of customer satisfaction. On the political level, when government organizations have good corporate reputation, the level of overall public trust is maximized. With a high level of public trust, citizens are more willing to participate in political affairs such as elections, opinion polls and public surveys. Furthermore, government organizations' reputations indicate their ability to respond to the global changes and local requirements for both flexible regulations and quality services (Da Silva and Batista, 2007).

Employees inherit their organizations' reputations. And in return, an organization's reputation is affected by its employees' individual behaviors and deeds (Luoma-aho, 2008). Corporate reputation, in essence, is created and affected by multiple interactions between the organization and its stakeholders (Da Silva \& Batist, 2007). Such interactions are undertaken by an organization's employees. For these considerations, organizations must be concerned with enhancing and maintaining good corporate reputation.

Reputation management is mainly the responsibility of human resource departments (Schultz and Werner, n. d.). It involves developing policies, procedures, and guidelines to handle certain situations that have direct effect on the corporate reputation. It also involves training managers to maintain the reputation level. Most importantly, top management must take up the responsibility of managing and maintaining an organization's reputation (Schultz and Werner, n. d.).

\section{Methodology}

Hypothesis testing is used to test the researcher observations. The observations were reduced to 3 hypotheses as follows:

H1: private-sector employees have negative stereotypical views about public-sector employees’ performance

H2: public sector employees know about the negative stereotypes held by private-sector employees about their performance

H3: public sector employees experience emotions of frustration by the negative stereotypes held by private-sector employees about their performance

Two self-administered questionnaires were designed, one for the private sector employees to survey their perceptions about the public sector employees' performance, and the other one for public sector employees to 
survey whether they are aware about these stereotypes, and whether this awareness produces emotions of frustration. The questionnaires included demographic questions, close-ended questions and one open question for remarks. The Likert scale was used for close-ended questions to seek the respondents' opinions on a list of statements.

A content-validity test was applied on the questionnaires using the consultancy of $3 \mathrm{PhD}$ holders and one lecturer. The questions were then modified according to their feedback. The reliability of the data was estimated using Crombach's Apla measure for internal consistency. Both questionnaires produced more than 0.7 , which is the acceptable level of reliability.

Due to the lack of availability of a sample frame from which a probability sample could be drawn, a non-probability sample strategy was employed. To find a wide mixture of employees in each sector, the questionnaires were distributed at two popular training centres that are accessible to all employee levels and organization types; Bahrain Institute for Baking and Finance and Bahrain Institute for Public Administration. After filtering the uncompleted questionnaires, 80 completed responses for each sector were entered in the database and considered for data analysis.

The questions from both questionnaires were mapped to the hypotheses. Chi-square goodness of fit method was used. The responses for all of the questions in the questionnaires were tested using a significance level of $\mathrm{a}=0.05$. All questions produced Chi-square values above the critical value at 4 degrees of freedom.

\section{Results}

Both samples have a good representation for both sexes. The respondents from the public sector work at 19 different organizations, and respondents from the private sector work at 43 different organizations. According to the median values for years of experience, 6 years for public sector and 7 years for private sector, the samples are reasonably comparable.

Table 1

\begin{tabular}{ccc}
\hline Respondents' Demographics & Public & Private \\
& Sector & Sector \\
\hline Females & $58 \%$ & $48 \%$ \\
Males & $42 \%$ & $52 \%$ \\
\hline Median age & 31.5 & 29.5 \\
\hline Median total years of experience & 6 & 7 \\
\hline Possess experience at the public sector & $100 \%$ & $11 \%$ \\
\hline Median years of experience at the public sector & 6.7 & 3.5 \\
\hline
\end{tabular}

Hypothesis One: 
Graph 1

To what extent do you agree that public sector services are not up to the standard?
Graph 2

To what extent do you agree that the quality of public sector services is a direct result of public sector employees?
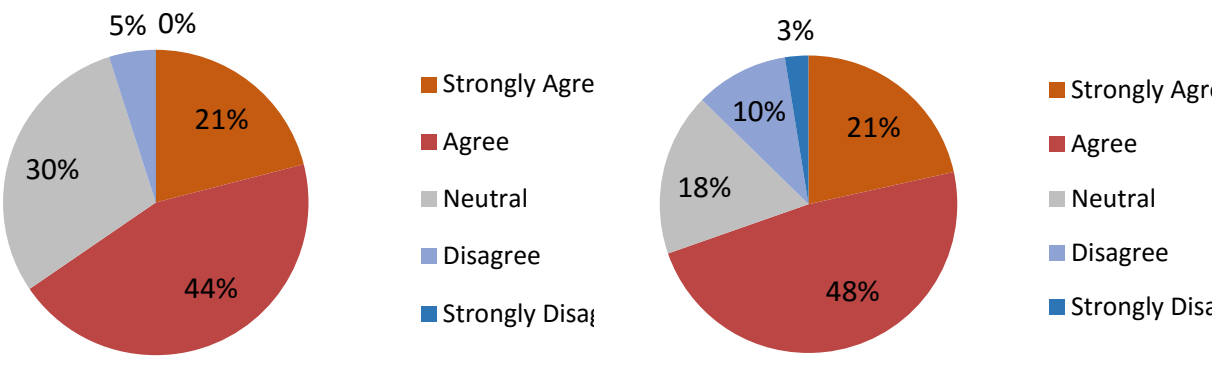

Hypothesis Two:

H1 stated that the private-sector employees have negative stereotypical views about public sector employees' performance. In order to test this hypothesis, we asked private sector employees about their perceptions on public sector employees' performance, and then we asked about the source from which they acquired these perceptions. The results show that $65 \%$ of the private sector respondents perceived public sector services as below the standard (21\% strongly agreed, and $44 \%$ agreed). A larger portion of the respondents attributed the deterioration in quality of the public sector service to the public sector employees; 69\% (21\% strongly agreed and $48 \%$ agreed). Using these results, we confirm that the private sector employees have a generic negative view about the public sector employees' performance.

Coming to the source of these views, $49 \%$ of the private sector respondents stated that they acquired their views from personal experience, $45 \%$ from ongoing views of friends and family, and 6\% from the media. Totaling the views resulting from ongoing views of others and media make up $51 \%$, which is the percentage of views that can be accepted as a stereotype. Notwithstanding a view gained from one or even multiple interactions with a few government organizations can indeed qualify as a stereotype if overly generalized as expressed in our questionnaire responses. And hence, $\mathrm{H} 1$ is validated.

H2 states that public sector employees know about the negative stereotypes held by private sector employees about their performance. The public sector questionnaire included a question that directly asked the respondents whether they were aware of negative perceptions held by the private sector employees about their performance. $80 \%$ of the respondents agreed (30\% strongly agree, and 50\% agree) that they were aware of these perceptions. Accordingly, H2 is validated. 


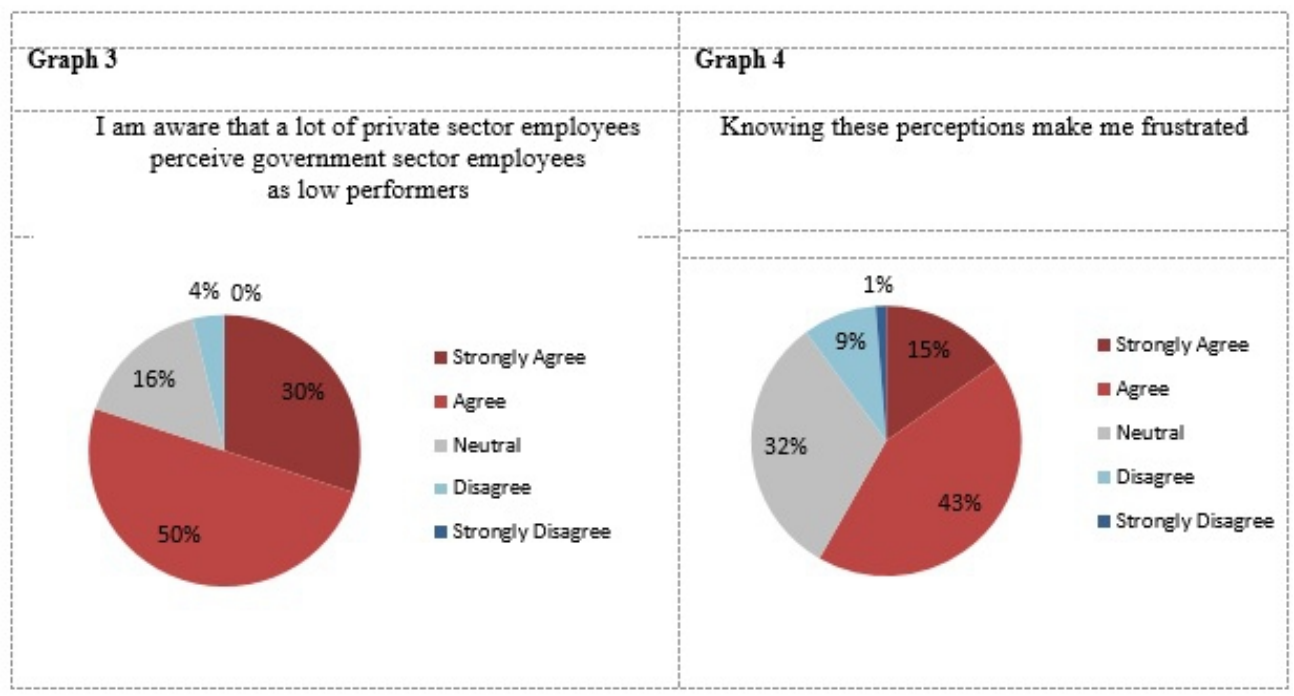

Hypothesis Three:

H3 states that public sector employees experience emotions of frustration caused by the negative stereotypes held by private-sector employees about their performance. Public sector respondents were asked a direct question whether knowing these perceptions pay them emotions of frustration; $15 \%$ strongly agreed and $43 \%$ agreed totaling $58 \%$. Bearing in mind that the question was about an intense emotion such as frustration as opposed to disappointment or discomfort, $58 \%$ make up relatively high percentage. This validates H3.

\section{Discussion}

\section{A clear theme of customer dissatisfaction}

As for the private sector respondents that gained their views about public sector employees' performance from personal experience, a clear customer dissatisfaction theme emerged in their remarks. Although most of the questions were about the performance of the public sector employees as individuals, comments and suggestions about improving customer service as an operation, and cultivating its culture were explicitly expressed. In addition, respondents complained about lack of customer service culture and employees being unable, or unwilling, to attend to their inquiries or complete their transactions in one visit.

This implies that the customer service offices fundamentally affect the organization's reputation. Private sector employees' views were confined by impressions gained from interactions with the government organization's front offices, disregarding the major scope to which the public sector's works extends. 
Accordingly, the stereotype held by the private sector employees clearly represents a manifestation of frustration with the public sector front offices. Hence we conclude that this stereotype is not deeply embedded. While we acknowledge that the excessive generalization made by private sector respondents is not wise, we cannot conclude that they maintain a belittling look for the employees of the public sector.

Furthermore, we asked a number of probing questions about the performance of public sector employees in order to aid the respondents to reflect on their generic views. For example, we asked "to what extent do you agree that the public sector employees voluntarily stay overtime hours when their work requires?" 26\% strongly agreed and 33\% agreed totaling 59\%. These results reflect a positive view about the public sector employees' performance. However, the responses to the other probing questions were not that positive. For example, the responses to a question asking "to what extent do you agree that public sector employees are committed to developing their skills?" included 5\% strongly agree, $16 \%$ agree, and a striking $41 \%$ neutral. With the same slant towards the neutral option, the responses to the question asking "to what extent do you agree that public sector employees are equipped with the right work behaviors?" included 4\% strongly agree, 10\% agree, and 38\% neutral.

These results can be interpreted in two manners. One on hand, one can argue that the private sector respondents are not keen to form and express an opinion about the subject in hand. Especially that 25\% strongly disagreed, and $46 \%$ disagreed that public sector administration requires high level of excellence in its employees' performance. On another hand, it could be argued that reverting to neutral reflects a withdrawal by some respondents from an unfair viewpoint about the subject in hand to more objectivity and readiness to reconsider.

Public sector employees- a culture of blame or distorted self-image?

Strangely enough, while $69 \%$ of the private sector respondents attributed the deterioration of the public sector services to the performance of its employees, $86 \%$ of the public sector respondents blamed the organizational environment for its employees' performance. Furthermore, $65 \%$ of the public sector respondents agreed that the private sector employees' negative perceptions are based on reality.

These findings are puzzling, and invite further research. We do not question that the private sector employees hold stereotypical views about their fellows in the public sector. This is because their views are gained from other people or resulted from inapplicable generalizations of personal experiences. Nonetheless, we clearly see that public sector employees themselves hold negative views about the performance of their own sector. 
The quandary continues as $87 \%$ of the public sector respondents agreed that they often try to impress their line managers by exceeding their expectations, $76 \%$ agreed that they are willing to stay overtime hours when work requires them to do so, and $82 \%$ agreed that they are motivated to improve their skills in order to improve their performance. On one hand, one can argue that the respondents are all exceptional performers that answered the questionnaire while being in training classes. However, looking holistically at the findings one can deduce that public sector employees are appealed to blaming the environment for the overall performance.

This deduction is supported when examining the behavior of the public sector respondents to the phrasing of the questions. Questions that asked the respondents to indicate something about their own performers such as "I am willing to stay overtime hours" and "I am willing to impress my line manager" yielded highly positive results, while questions that invited them to evaluate the overall problem such as "I believe that the public sector employees can perform at a high level but the government environment discourages them" revealed a rather gloomy outlook. In our view, such contradiction may have resulted from a culture of blame in which they believe that they can perform, but some external force is discouraging them. This contradiction may also reflect a distorted self-image that they maintain with regards to their performance.

\section{Conclusion and practical implications}

The research results imply that private sector employees blame the public sector employees for the deterioration of the public sector services. Nonetheless, the stereotypical views that private sector employees hold are not deeply embedded. As opposed to the motives offered by the literature for stereotyping, the results suggest that the stereotype in hand is a result of private sector employees being dissatisfied with the treatment they get as customers of some government organization's front offices.

Despite our findings that the stereotypes were not deeply embedded, fundamental effects on the sampled public sector employees were found. The results showed that public sector employees contemplated their own performance in separation from that of their organizations. This suggests decreased levels of self-esteem, self-confidence, and self-efficacy. Further research is required on the stereotypes inherited from the organization's reputation and their psychological and behavioral effects on the stereotype subjects.

These findings emphasize the importance of maintaining good corporate reputation for government organizations. All public sector employees have inherited the reputation of their organizations' front offices. And hence, if government organizations improve their corporate reputations 
by promoting their frontline services, the stereotypes held about their employees can possibly change. These findings agree with the literature on the importance of investing in their corporate reputations.

\section{Originality}

This research uses an original approach as it addresses the stereotypes from two points of views; the view point of the group that maintains them, and the view point of the group that is subjected to them. Furthermore, it is also the first in addressing stereotypical views held by employees of one economic sector about the performance of employees of another sector.

\section{Limitations \& future research}

This research explored the stereotypes held by the private sector employees only. Future research can explore these stereotypes in a sample from general society. Especially when considering that $45 \%$ of the private sector respondents pointed that they gained their views from ongoing views of friends and family. Furthermore, generalizations of this research results must be made with attention to the region. The sample is limited to the Kingdom of Bahrain. Future research can test the same hypotheses on a bigger region of the Middle East, or other places in the world to enable a safe generalization.

In addition, this research does not identify the origins of these stereotypes. Future research can consider using constructivist epistemology to detect the roots of the phenomenon and provide an explanatory account for it.

\section{Acknowledgments:}

The authors would like to acknowledge the following:

Bahrain Institute for Public Administration's management and staff, especially the Registration Department staff for providing access to the public sector respondents and administering the questionnaires.

Dr. Vijaya ----- CIPD Programme Manager at the Bahrain Institute for Banking and Finance

Dr. Vivik Kumar SLM Programme Manager at the Bahrain Institute for Banking and Finance

Dr. Mohammed Farouq Head of the Research Centre of the Bahrain Institute for Banking and Finance

Mr. Kadri Rizk Lecturer at the Leadership and Management Centre at the Bahrain Institute for Banking and Finance

For checking the initial versions of the questionnaires for the validity testing. 


\section{References:}

Allison, S. T., Beggan, J. K. \& Carolyn Clements, (2004) "Derogatory stereotypic beliefs and evaluations of male nurses", Equal Opportunities International, 23(3/4/5): 162-178

Argyle, M. (1994) "The Psychology of Interpersonal Behaviour", fifth edition, Penguin books

Buyens, D., Dijk, H. V., Dewilde, T. \& De Vos, A. (2009) "The aging workforce: perceptions of career ending", Journal of Managerial Psychology, 24(2): 102-117

Casimir, M. J. (2008) "Culture and the changing environment", first edition, Berghahn Books

Conaway, C. (2005) "a Psychological Effect of Stereotypes" Regional Review, 2005(Q1): 40-41

Croizet, J.C. (1998) "Extending the Concept of Stereotype Threat to Social Class: The Intellectual Underperformance of Students from Low Socioeconomic Backgrounds" Personality and Social Psychology Bulletin; 24(6): 588-594

Da Silva, R. \& Batista, L. (2007) "Boosting government reputation through CRM", International Journal of Public Sector Management, 20(7): 588-607 Devine, P. G. (1989) "Stereotypes, and Prejudice: Their Automatic and Controlled Components" Journal of Personality and Social Psychology. 56(1): 5-18

Evans, L. \& Fraser, I. (2012) "The accountant's social background and stereotype in popular culture: The novels of Alexander Clark Smith", Accounting, Auditing \& Accountability Journal, 25(6): 964-1000

Fernandes, E. \& Cabral-Cardoso, C. (2003) "Gender asymmetries and the manager stereotype among management students", Women in Management Review, 18 (1/2): 77-87

Fogliati, V. J. \& Bussey, K. (2013) "Stereotype Threat Reduces Motivation to Improve: Effects of Stereotype Threat and Feedback on Women's Intentions to Improve Mathematical Ability" Psychology of Women Quarterly, March 22, 2013 0: 0361684313480045v1-361684313480045

Kenrick, D.T., Neuberg, S.L., Cialdini, R.B. (2002) Social Psychology: Unraveling the Mystery,

Leitner, J. B., Jones, J. M., \& Hehman, E. (2013) "Succeeding in the Face of Stereotype Threat- The Adaptive Role of Engagement Regulation" Personality and Social Psychology Bulletin, 39(1): 17-27

Luoma-aho, V. (2008) "Sector reputation and public organisations", International Journal of Public Sector Management, 21(5): 446-467

Luthmann, A. (2007) "Librarians, professionalism and image: stereotype and reality", Library Review, 56(9):773-780 
Martin, D. E., Moore \& C. F., Hedgspeth, C (2009) "The unobtrusive knowledge test: validity and stereotype threats", Equal Opportunities International, 28(7): 577-590

McGarty, C., Yzerbyt, V. Y., \& Spears, R. (2002) "Stereotypes as Explanations- The Formation of Meaningful Beliefs about Social Groups" Cambridge University Press, ISBN 0-521-80047-1

Schultz, H. B. \& Werner, A. (n. d.) "Reputation Management" Oxford University Press- South Africa, www.oxford.co.za

Walter, B. F. (2006) " Building Reputation: Why Governments Fight Some. Separatists but Not Others" American Journal of Political Science, 50(2): 313-330, ISSN 0092-5853

(2007) "Humble public sector managers lack leadership confidence", Women in Management Review, 22 (8)

Wimmer, R. D. \& Dominick, J. R."Mass Media Research - An Introduction”, 2004, 8th edition Wadsworth Cengage Learning

Valiulis, M., O’Driscoll, A., \& Jennifer Redmond (2007) "An Introduction to Gender Equality Issues in the Marketing and Design of Goods for Children", Equality Authority, ISBN: 0-88033-999-3 